Corn silk methanolic extract improves oxidative stress and inflammatory responses in rats' excision wound model

A.O. Oyabambi, A.B. Nafiu*, A. Okesina, S.S. Babatunde, E.K. Dominic and D.O. Oreoluwa

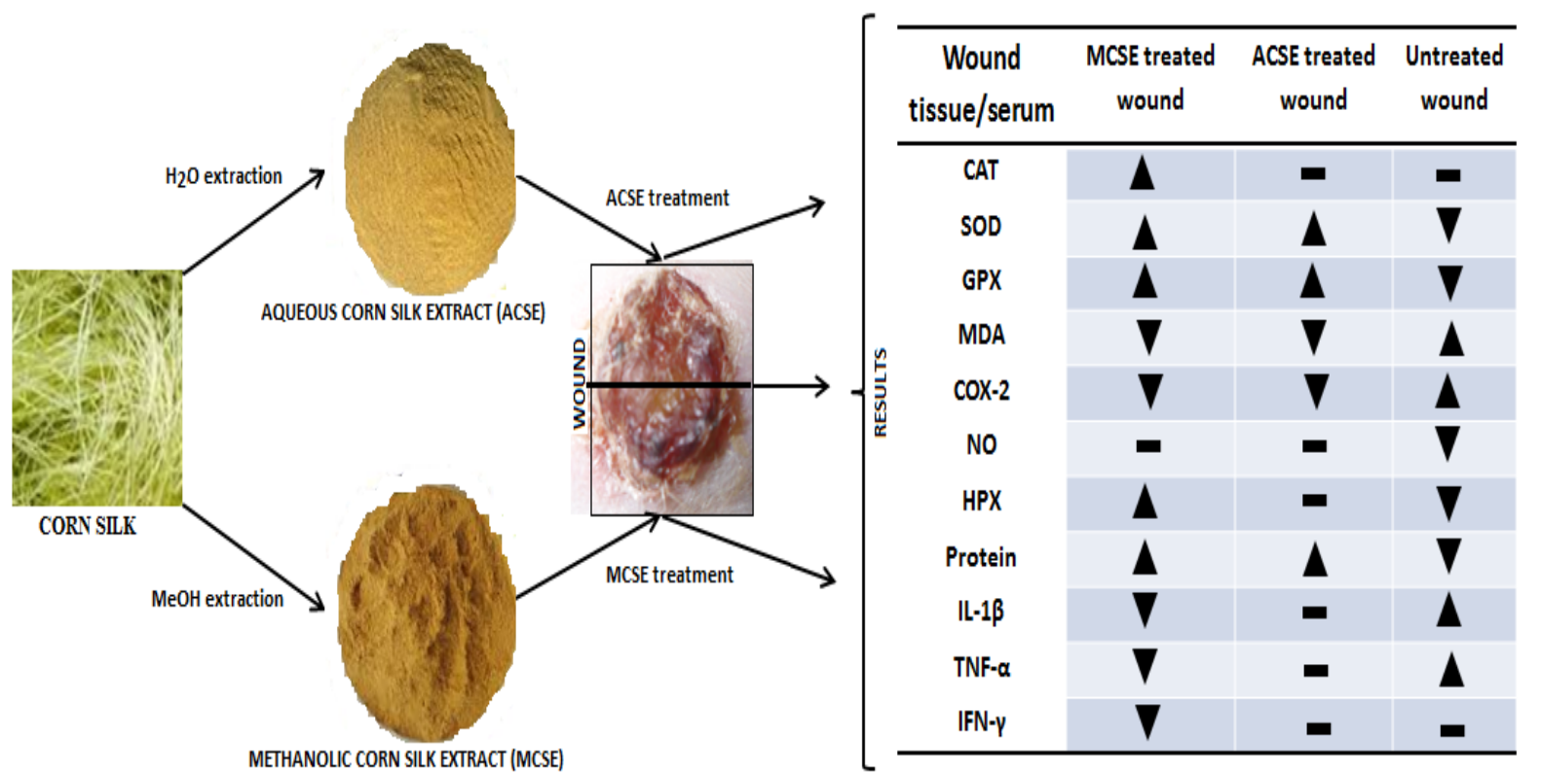

Highlights

- Wound presents two major conditions; oxidative stress and inflammatory response.

- Corn silk extract suppressed oxidati.ve stress by limiting lipid peroxidation.

- Corn silk extract reduces inflammation by inhibiting cytokines release in rat.

- Methanolic extract produced a notable effect relative to aqueous extract. 
RESEARCH ARTICLE

\title{
Corn silk methanolic extract improves oxidative stress and inflammatory responses in rats' excision wound model
}

\author{
A.O. Oyabambi ${ }^{1}$, A.B. Nafiu ${ }^{2 *}$, A. Okesina ${ }^{3}$, S.S. Babatunde ${ }^{1}$, E.K. Dominic ${ }^{1}$, D.O. Oreoluwa ${ }^{1}$ \\ ${ }^{1}$ Department of Physiology, College of Health Sciences, University of Ilorin, Ilorin, Nigeria. \\ ${ }^{2}$ Department of Human Physiology, College of Health Sciences, Federal University Dutse, Jigawa, Nigeria. \\ ${ }^{3}$ Department of Human Anatomy, Faculty of Biomedical Sciences, Kampala International University, Uganda.
}

Received: 02/07/2020; Accepted: 04/02/2021

\begin{abstract}
Anti-inflammatory and antioxidant activities of corn silk (Stigma maydis of Zea mays L.) extract were investigated in excision wound model. Twenty male Wistar rats $(130-150 \mathrm{~g})$ were grouped into four ( $\mathrm{n}=5$ /group): Control rats received 0.5 $\mathrm{mL}$ distilled water, the experimental groups received distilled water $(0.5 \mathrm{~mL})$, aqueous corn-silk extract (ACSE; $500 \mathrm{mg} / \mathrm{kg}$ ) and methanolic corn-silk extract (MCSE; $500 \mathrm{mg} / \mathrm{kg}$ ), twice/day orally, three weeks before and three weeks after they had $1.5 \times 1.0$ $\mathrm{cm}$ excision wound. Rats were sacrificed and blood was collected. Serum was separated while wound tissues were removed, homogenised and supernatant was stored. Antioxidant enzymes, malondialdehyde, hydroxyproline, cyclooxygenase- 2 and NO were measured in wound tissues colorimetrically, while serum cytokines were measured using enzyme linked immunosorbent assay. MCSE significantly $(\mathrm{p}<0.05)$ increased glutathione peroxidase, superoxide dismutase, catalase, hydroxyproline and total protein content but decreased significantly $(\mathrm{p}<0.05)$ malondialdehyde, cyclooxygenase- 2 , IL- $1 \beta$, TNF- $\alpha$, and IFN- $\gamma$ when compared with untreated wound. ACSE increased significantly $(\mathrm{p}<0.05)$ glutathione peroxidase and superoxide dismutase but decreased significantly $(\mathrm{p}<0.05)$ malondialdehyde and cyclooxygenase-2. However, it produced no significant effect on catalase, IL-1 $\beta$, TNF- $\alpha$, and IFN- $\gamma$ when compared with untreated wound. MCSE attenuated oxidative and inflammatory responses in excision wound rat model.
\end{abstract}

Keywords: Corn silk extract; antioxidant enzymes; antiinflammation; cytokines; wound healing.

\section{INTRODUCTION}

Wound healing is a natural restorative response to tissue injury. It involves complex cellular events, characterised by four overlapping programmed phases: hemostasis, inflammatory/defensive reaction, proliferation and remodeling (Sorg et al., 2017; Gilmore, 1991). In response to injury, the inflammatory cells infiltrate the wound site and release pro-inflammatory cytokines and growth factors (Nayaket al., 2009). The cytokines released are essential as autocrine regulators of macrophage activation and differentiation (Witsell and Schook, 1992). The inflammatory cells also undergo respiratory burst at the wound site to enhance release of reactive oxygen species (ROS) which further stimulate and reinforce inflammatory cell recruitment, phagocytosis and the release of growth factors necessary for the progression of wound healing to repair phase (Hoffmann and Griffiths, 2018). Delayed acute wound healing and chronic non-healing wounds fail to progress through "inflammation-repair switch" and remain stuck at inflammation phase. The pro-inflammatory cytokines are exuberantly produced in response to impeding factor which uncontrollably activate the inflammatory cells such as polymorphonuclear leukocytes to excessively release reactive oxygen species thereby causing tissue oxidative damage and delay wound repair. As the wound becomes flooded with pro-inflammatory cytokines and products of tissue breakdown, the alternative macrophage differentiation is also disrupted resultantly leaving the wound tissue in the state of "vicious cycle" between inflammation and oxidative tissue breakdown. These form the basis for investigating therapeutic agents that can potentially control pro-inflammatory cytokine release while limiting tissue oxidative damage during the late-inflammatory phase of wound repair (Hoffmann and Griffiths, 2018).

Delayed acute wound and chronic wound have been estimated to affect $1-2 \%$ of the population during their life time in developed countries (Järbrink et al., 2016). It has been estimated that close to sixmillion people have chronic non-healingwound every year in the United States (Guo and Di Pietro, 2010). Wound healing impairment has become one of the leading causes of death in Africa due to road and household accidents, wound infection, underlying organic conditions and poor health care system(Guo and DiPietro, 2010). Therefore, it is imperative to investigate affordable and accessible alternative therapeutic agent that can potentially enhance wound healing by targeting the inflammatory markers, tissue oxidative breakdown and antioxidant factors during wound healing. Corn silk extractis one of the locally available plants' natural products that have been consistently shown to have a remarkable anti-inflammatory and antioxidant potential.

Corn silk (Zea mays L.; Stigma maydis) is a bunch of hair-like strands of stigma from the female flower of maize and it constitutes a large body of waste material from corn cultivation that is available in abundance (Hasanudin et 
al., 2012; Maksimovíc et al., 2005). It is a classical herb in traditional Chinese medicine that has many therapeutic properties and has been used for a long time as a remedy for various illnesses (Hu and Deng, 2011). Corn silk has a long history of application in traditional medicine in many parts of the world including Turkey, China, France and United States. It is used for the treatment of conditions associated with inflammation such as oedema, cystitis, gout, nephritis and prostatitis (Hu and Deng, 2011). The medicinal value of corn silk can be linked with its phytochemical constituents. It is an excellent source of many bioactive phytochemicals such as flavonoids, saponins, alkaloids, tannins, chlorogenic acid, phytosterols, allantoin, vitamin E and vitamin K (Haslina and Eva, 2017). Corn silk extract improved endothelial dysfunction in uric acid induced metabolic derangement of high salt-fed Wistar rats (Witte and Barbul, 2002). Reports have also shown that corn silk is beneficial for the treatments of fatigue, depression, and can be used as kaliuretic (Hu and Deng, 2011, Thoudam et al., 2011, Bump and Brown, 1990). Recently, corn silk extract reportedly inhibited activities of pro-inflammatory cytokines and improved carrageenan induced pleurisy (Wang et al., 2012). The methanol extract also showed antioxidant activity by inhibiting lipid peroxidation (Marty, 1999). Therefore, based on previous studies, the antioxidant and anti-inflammatory activities of corn silk extracts (aqueous and methanolic) were evaluated in rats' excision wound model.

\section{MATERIALS AND METHODS}

\section{Ethics statement}

The animal handling and management procedure were as prescribed in the guidelines for the care and use of laboratory animals of University of Ilorin and the study protocols were approved by University of Ilorin Ethical Review Committee (UERC/ASN/2016/357).

\section{Chemicals and reagents}

Glutathione peroxidase enzymatic assay kit was purchased from Fortress (Fortress Diagnostics Limited, UK). The rat cytokines ELISA kits used are products of BDBiosciences, US. Thiobarbituric acid reactive substance (TBARS), methanol, protein assay kit, hydroxyproline, $\mathrm{NaNO}_{2}$, bovine serum albumin (BSA), Bradford reagent, malondialdehyde (MDA), N-naphtyl ethylene diamine dihydrochloride, phosphate buffered saline tablet, sulphanilamide, trichloroacetic acid, tris-HCL and zinc sulphate were purchased from Sigma (St. Louis, MO, USA). Ethyl ether, hydrogen peroxide $\left(\mathrm{H}_{2} \mathrm{O}_{2}\right)$, potassium hydroxide, potassium permanganate, sodium chloride, sodium hydroxide and sulphuric acid reagent $\left(\mathrm{H}_{2} \mathrm{SO}_{4}\right)$ were obtained from Merck (Merck, Darmstadt, Germany). Pyrogallol was purchased from Santa cruz (Santa Cruz, CA, USA). Colorimetricbased COX activity assay kit was obtained from Cayman (Cayman, Ann Arbor, MI, USA) and tissue lysis buffer was procured from Thermo Fisher Scientific (Thermo Fisher Scientific, Waltham, MA).

\section{Plant material}

Mature fresh maize (Zea mays L.) of the cultivar 'Oba Super9', belonging to the family Poaceae or Gramineae, was obtained from Oke Oyi Farm in Ilorin-East LGA, Ilorin, Nigeria. The husks were immediately removed and fresh corn silks (Stigma maydis) were collected in August, 2019. The maize was identified and authenticated by Mr. Bolus Ajayi of Department of Plant Biology, Faculty of Life Science, University of Ilorin, Ilorin Nigeria with a voucher specimen UILH/001/1219 deposited at the Herbarium of the Faculty of Life Science, University of Ilorin for future reference.

\section{Corn silk extracts preparation}

Freshly collected Stigma maydis $\sim 50 \mathrm{~g}$ was thoroughly washed with distilled water, cut into shreds and air dried at room temperature for seven days and then dissolved in $200 \mathrm{~mL}$ of $100 \%$ methanol $(\mathrm{MeOH})$ in a conical flask according to the methods by Oyabambi et al., (2019). This was then placed in a shaker for approximately $120 \mathrm{~h}$ at $28 \pm 2{ }^{\circ} \mathrm{C}$. The resulting extracts were then transferred to clean vessels, evaporated to dryness. After pulverization, $100 \mathrm{~g}$ of the extract was soaked in $1 \mathrm{~L}$ of distilled water for $72 \mathrm{~h}$, and then concentrated using a water bath. This was done repeatedly until the required stock solution was obtained. The methanol extract was obtained using a rotatory evaporator after $150 \mathrm{~g}$ of the pulverized corn silk was soaked in $1.5 \mathrm{~L}$ of $80 \%$ methanol for $24 \mathrm{~h}$. The extract was diluted in distilled water and administered at a dose of $500 \mathrm{mg} / \mathrm{kg}$ body weight per oral (p.o.).

\section{Animals}

Twenty male adult Wistar rats with mean weight of 140 $\pm 10 \mathrm{~g}$ were acquired from the Animal Holding unit of the Faculty of Basic Medical Science, University of Ilorin, Ilorin, Nigeria. Rats were left to acclimatize with the laboratory environment for a period of seven days during which they were fed pellet form of grower feed (Vital poultry feed, Ilorin, Nigeria) and tap water ad libitum. Throughout the course of the experiment, the animals were housed in clean cages and kept under standard housing conditions (National Research Council, 2011).

\section{Wound induction and treatments}

Twenty rats were randomly assigned into four groups of five rats per group ( $\mathrm{n}=5 /$ group): (i) Control (distilled $\mathrm{H}_{2} \mathrm{O}$ )-treated normal group, (ii) excision wound-inflicted (wounded) and treated with distilled $\mathrm{H}_{2} \mathrm{O}$ group, (iii) excision wound-inflicted and aqueous corn-silk extract (ACSE $500 \mathrm{mg} / \mathrm{kg}$ body weight)-treated group, and (iv) excision wound-inflicted and methanol corn-silk extract (MCSE $500 \mathrm{mg} / \mathrm{kg}$ body weight)-treated group. The selected dose was based on the previous studies by Wang et al., (2012); Ha et al., (2018); and Kim et al., (2019). It was shown that Corn silk extract, administered per oral (p.o.) for 14 days in the dose range of $0.5-4 \mathrm{~g} / \mathrm{kg}$, was safe in rats and that corn silk extract at dose up to $500 \mathrm{mg} / \mathrm{kg}$ produced no sign of organ toxicity during sub-acute toxicity testing for four weeks. The rats were orally treated two times per 
day according to the treatment groups for three weeks before excision wound induction.

After three weeks of treatment, the dorsal region of the fifteen experimental rats' left thigh was shaved after the administration of light ethyl ether anaesthesia. The wound incision of $1.5 \times 1.0 \mathrm{~cm}$ was induced on the animals while the control had no wound incision. The control rats continue to receive $0.5 \mathrm{~mL}$ (twice/day; p.o.) distilled water without wound induced on them. The experimental groups also continue to receive distilled water $0.5 \mathrm{~mL}$ (twice/day; p.o.), aqueous corn-silk extract (ACSE $500 \mathrm{mg} / \mathrm{kg}$ body weight twice/day; p.o.) and methanol corn-silk extract (MCSE $500 \mathrm{mg} / \mathrm{kg}$ body weight twice/day; p.o.) for three weeks after excision wound was induced i.e. distilled water and the extracts were administered twice/day; p.o., three weeks before and three weeks after excision wound induction.

\section{Sample collection and preparation}

After six weeks of treatment, rats were anesthetized with deep ethyl ether anaesthesia. Blood was collected by cardiac puncture into plain bottles and was left to clot. Serum was separated by centrifugation at $3000 \mathrm{rpm}$, at room temperature for five minutes and stored at $-20{ }^{\circ} \mathrm{C}$ until use for biochemical assays of inflammation markers (IL-1 $\beta$, TNF- $\alpha$, IFN- $\gamma$,). Wound granulation tissues were also carefully removed as previously reported (Nafiu and Rahman, 2015), weighed, homogenised in ice-cold sodium phosphate buffer $\left(0.01 \mathrm{moldm}^{-3}, \mathrm{pH}\right.$ 7.4) and centrifuged at $12000 \times \mathrm{g}$, and $4^{\circ} \mathrm{C}$ for five minutes. The supernatant was collected and kept at $-20^{\circ} \mathrm{C}$ until use for the biochemical estimations of wound tissue total protein, antioxidant factors; glutathione peroxidase (GPx; EC 1.11.1.9), superoxide dismutase (SOD; EC 1.15.1.1), catalase (EC 1.11.1.6), oxidative stress marker (malondialdehyde; MDA), cyclooxygenase-2 (COX-2; EC 1.14.99.1), NO, and hydroxyproline contents, an index of collagen turnover synthesis that is correlated to wound tensile strength (breaking force). Protein content was quantified following Bradford standard method (Bradford, 1976).

\section{Biochemical estimations of catalase, superoxide dismutase and glutathione peroxidase}

Catalase activity was measured using spectrophotometric method as described by Cohen et al., (1970). The rate of $\mathrm{H}_{2} \mathrm{O}_{2}$ degradation by the addition of collected supernatant to standard excess of $\mathrm{KMnO}_{4}$ was determined by allowing the reaction to continue for three minutes and measuring the absorbance of the residual $\mathrm{KMnO}_{4}$ at $480 \mathrm{~nm}$. In this assay, 1 unit of enzyme activity equals $\mathrm{k} /(0.00693)$, where $\mathrm{k}=\log$ $\left(\mathrm{S}_{0} / \mathrm{S}_{2}\right) \times(2.3 / \mathrm{t}), \mathrm{S}_{0}=$ absorbance of standard - absorbance of blank, $\mathrm{S}_{2}=$ absorbance of standard - absorbance of sample, and $\mathrm{t}=$ time interval (Aebi et al., 1974). Catalase activity was calculated as units per mg of sample protein concentration.

SOD activity was assessed according to the method of Marklund and Marklund, which is based on the ability of SOD to scavenge superoxide anion radical $\left(\mathrm{O}_{2}^{-}\right)$to inhibit the auto-oxidation of pyrogallol. Briefly, $50.0 \mu \mathrm{L}$ of the collected supernatant was mixed with $1.0 \mathrm{~mL}$ of $0.05 \mathrm{~mol}$ $\mathrm{dm}^{-3}$ Tris- $\mathrm{HCl}$ buffer ( $\mathrm{pH} 8.2$ ) containing $1 \mathrm{mmol} \mathrm{dm}^{-3}$ diethylenetriaminepenta-acetic acid and the reaction was initiated by the addition of pyrogallol. SOD activity was determined by measuring the absorbance kinetically at 420 $\mathrm{nm}, 25^{\circ} \mathrm{C}$ for 3 minutes with 1unit of SOD defined as the amount that inhibited the rate of pyrogallol autoxidation by $50 \%$ and adjusted per sample protein concentration (Marklund and Marklund, 1974).

GPx activity was measured using Glutathione peroxidase enzymatic assay kit (Fortress Diagnostics Limited, UK) following the manufacturer's instruction. It is based on the oxidation of reduced glutathione by the sample GPx. The oxidised glutathione is then reduced by the action of glutathione reductase and NADPH. In the reaction, 1 unit GPx causes the formation of $1.0 \mathrm{mmol}$ of NADP+ from NADPH per minute. Thus GPx enzyme activity was calculated as units per mg of sample protein concentration.

\section{Biochemical estimation of lipid peroxidation}

Lipid peroxidation (LPX) was evaluated based on the thiobarbituric acid reactive substance TBARS method as described by Buege and Aust (1978). Tissue sample was mixed with reaction solution containing $15 \%$ trichloroacetic acid, $0.375 \%$ thiobarbituric acid, and $0.25 \mathrm{~N} \mathrm{NaOH}$. The mixture was boiled at $100{ }^{\circ} \mathrm{C}$ for 10 minutes, and allowed to cool down to room temperature. The absorbance of the resulting solution was recorded at $532 \mathrm{~nm}$. LPX in the form of malondialdehyde (MDA) equivalent was expressed as $\mathrm{nmol} / \mathrm{mg}$ of the sample protein concentration.

\section{Biochemical estimations of IL-1 $\beta$, TNF- $\alpha$ and IFN- $\gamma$}

The serum concentrations of cytokines (IL- $1 \beta$, TNF- $\alpha$, and IFN- $\gamma$ ) were measured by respective rat enzyme-linked immunosorbent assay (rat-ELISA) kit according to the manufacturer's protocol (BDBiosciences, USA). In order to ensure reproducibility, the experiments were performed in triplicate and serum concentration of cytokines was determined in $\mathrm{pg} / \mathrm{mL}$ equivalent of the standard.

\section{Biochemical estimations of COX-2, NO and hydroxyproline}

A COX-2 colorimetric-based assay kit (Cayman, Ann Arbor, MI) was used to estimate wound tissue COX-2 enzyme activity according to the manufacturers' protocol.

Wound tissue NO level was estimated following a modified method reported by Batool et al., (2017). Briefly, Serum sample $(30 \mu \mathrm{L})$ was mixed with $0.3 \mathrm{M} \mathrm{NaOH}$ and $5 \% \mathrm{ZnSO}_{4}$. The mixture was centrifuged for 20 minutes at $6400 \times \mathrm{g}$ and supernatant collected. Supernatant $(10 \mu \mathrm{L})$ was mixed with $100 \mu \mathrm{L}$ of $1 \%$ sulfanilamide (dissolved in $1.2 \mathrm{~mol} \mathrm{dm}^{-3} \mathrm{HCl}$ ) and $100 \mu \mathrm{L}$ of $0.1 \% \mathrm{~N}$-naphtyl ethylene diamine dihydrochloride, and incubated for five minutes at room temperature. The absorbance was read at 540 $\mathrm{nm}$ using a microplate reader. Nitrite concentration was estimated using $\mathrm{NaNO}_{2}$ as a standard (Batool et al., 2017).

Wound tissue samples were oven-dried and hydrolyzed in $5 \mathrm{~N} \mathrm{HCl}$ for $12 \mathrm{~h}$ at $130{ }^{\circ} \mathrm{C}$ in closed tubes to measure the hydroxyproline content. Colourimetric-based assay, described by Reddy and Enwemeka (1996), was used to 
determine the hydroxyproline content of the hydrolysate containing $0.5 \mathrm{mg}$ of wound tissue samples. Hydroxyproline concentration was estimated in $\mu \mathrm{g} / \mathrm{mg}$ tissue equivalent of the standard and the absorbance was read at $560 \mathrm{~nm}$ in Lambda 25 UV/Vis spectrophotometer (Perkin Elmer, MA, USA) (Reddy and Enwemeka, 1996).

\section{Statistical Analysis}

Sample size was determined by the use of 'resource equation' method and the data were analysed using a statistical software package SPSS for Statistics version 20 (IBM, Armonk, NY) and expressed as mean \pm standard error of mean (mean \pm SEM). Means were compared by analysis of variance (ANOVA) followed by the Turkey's post-hoc test for multiple comparison. A p-value less than $0.05(\mathrm{p}<0.05)$ was considered as statistically significant.
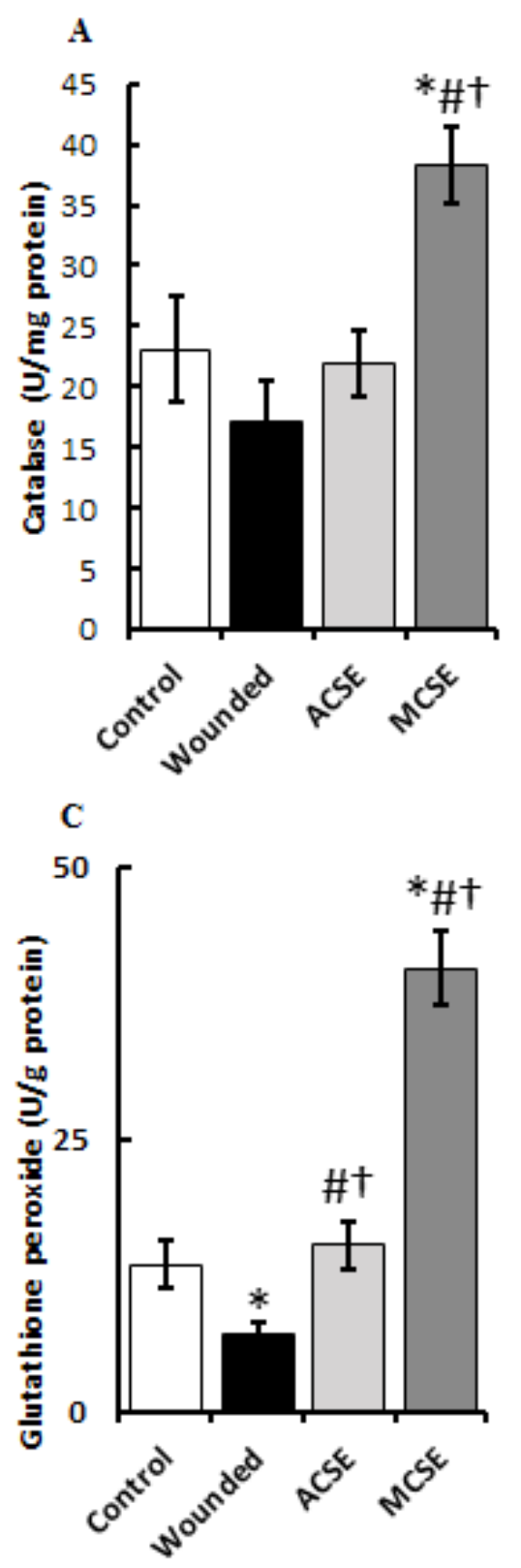

\section{RESULTS}

\section{Corn silk improved wound bed condition}

Corn silk extract treated groups showed no sign of oedema or exudate formation around the wound site, unlike the distilled water treated (wounded) group, throughout the experimental period. At day 1 post wounding, the distilled water treated group showed sign of edema with large amount of exudates formation in the form of pus which remains in three out of five rats until day 10 post wounding. The ACSE group also showed little signs of swelling on the day 1 however, the appearance of exudates was only noticed on the day five in one of the rats. Animals treated with MCSE exhibited "clean healing" as the wounds remain clean throughout the experimental period. It is also observed that time taken for scab shedding varies among the groups. The ACSE and MCSE treated groups shed

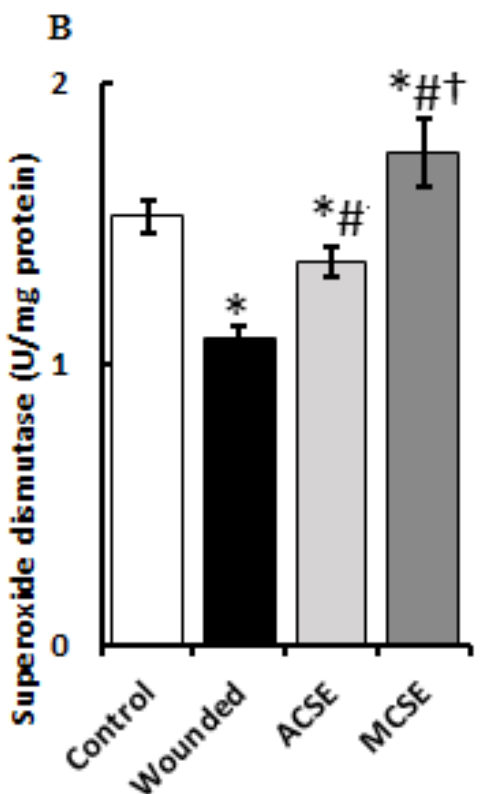

D

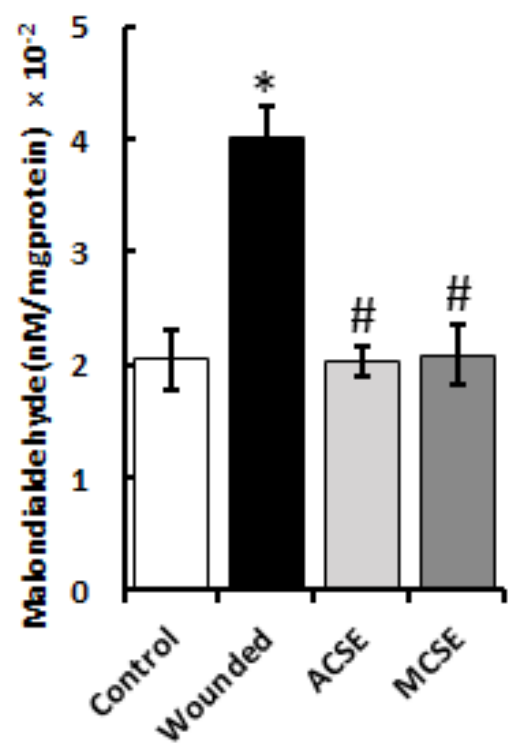

Figure 1: Catalase, superoxide dismutase and glutathione peroxidase activities and malondialdehyde in wound tissues following treatment with corn silk extracts.ACSE, aqueous corn silk extract; MCSE, methanolic corn silk extract. Bars indicate mean \pm SEM $(\mathrm{n}=5) ; *$, \#, and †indicate significant difference at $\mathrm{p}<0.05$ as compared with control, wounded and ACSE respectively. 
scab between day eight and day 10 post wounding while the distilled water treated groups shed scab between day seventeen and day twenty completely or partially. This result showed that corn silk extract prevented formation of macroscopic signs of inflammation in excision wound and prevented contamination to improve healing by reducing time for scab shedding.

\section{Corn silk enhances antioxidant enzymes activities but reduces malondialdehyde}

Wound induced altered endogenous antioxidant enzymes' (GPx, SOD and catalase) activities were restored to control level by ACSE. However, MCSE further increased the enzymes' activities significantly $(p<0.05)$ when compared with control, untreated wounded and ACSE-treated groups (Figure 1A-C). Both ACSE and MCSE, similarly and significantly $(\mathrm{p}<0.05)$, reduced plasma MDA when compared with the wounded group (Figure 1D).
Corn silk increases protein, NO and hydroxyproline but reduces cyclooxygenase-2

Untreated wound tissue exhibited significant $(\mathrm{p}<0.05)$ depletion in total protein, nitric oxide and hydroxyproline contents with remarkable upsurge in wound tissue cyclooxygenase-2 level when compared to the control group (Figure 2A-D). ACSE increased the wound total protein content and reduced cyclooxygenase enzyme activity in wound significantly $(\mathrm{p}<0.05)$ when compared to the wounded group (Figure 2A\&C). However, hydroxyproline and NO were not affected by ACSE treatment (Figure $2 B \& D)$. Treatment with MCSE significantly $(p<0.05)$ increased wound total protein, NO, and hydroxyproline contents but reduced significantly $(p<0.05)$ wound cyclooxygenase enzyme when compared to control, wounded and ACSE groups (Figure 2A-D). Except that MCSE improved wound protein and NO contents similar to ACSE and control respectively without marked changes
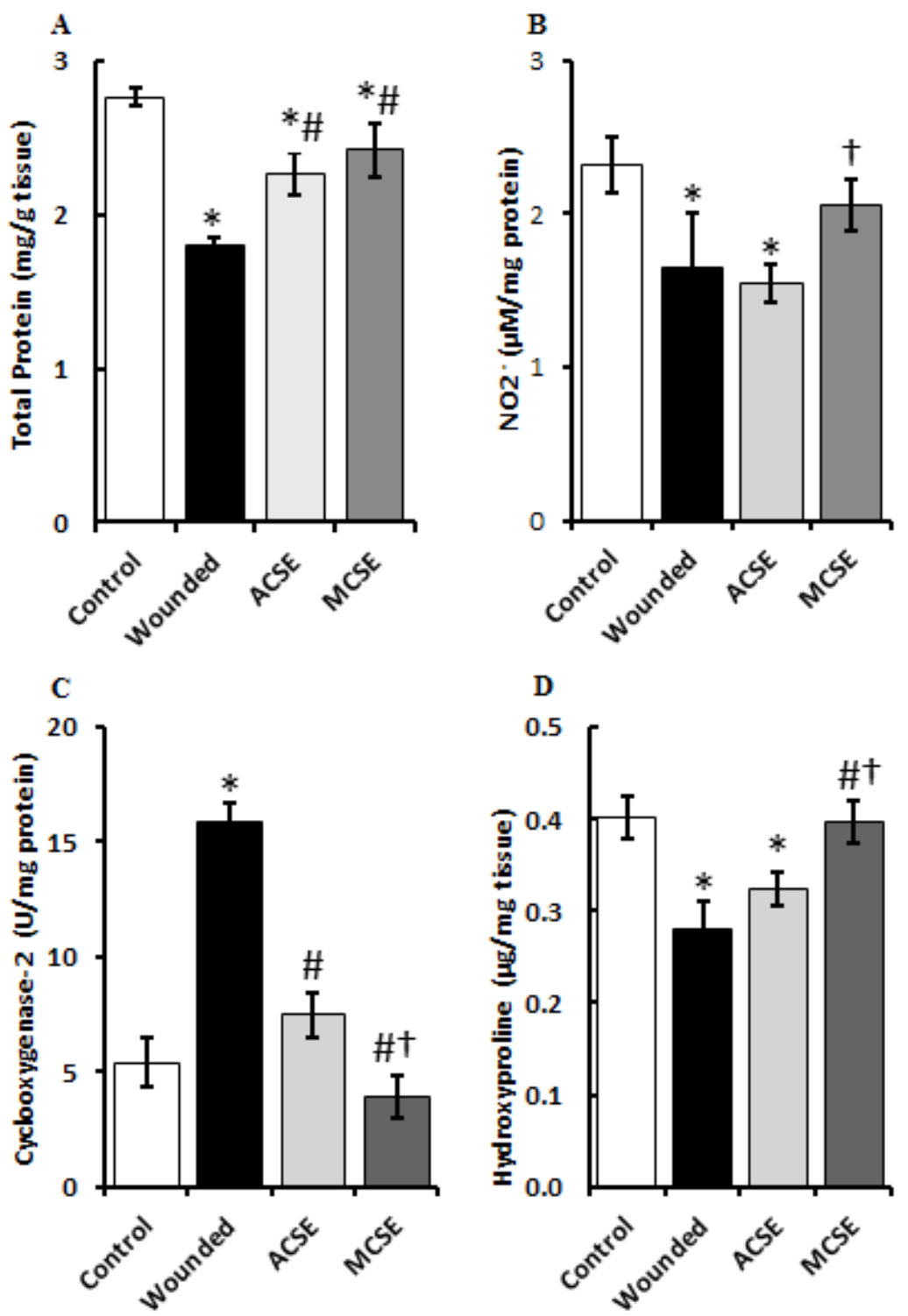

Figure 2: Total protein, nitrite $\left(\mathrm{NO}_{2}^{-}\right)$, cyclooxygenase-2, and hydroxyproline in wound tissues following treatment with corn silk extracts. ACSE, aqueous corn silk extract; MCSE, methanolic corn silk extract. Bars indicate mean $\pm \operatorname{SEM}(\mathrm{n}=5) ;{ }^{*}$, \#, and $\uparrow$ indicate significant difference at $\mathrm{p}<0.05$ as compared with control, wounded and ACSE respectively. 
in NO when compared with wounded but better than ACSE (Figure 2A \& B).

\section{Corn silk reduces IL-1ß, TNF- $\alpha$ and IFN- $\gamma$}

The elevated inflammatory markers (IL-1 $\beta$, TNF- $\alpha$, and IFN- $\gamma$ ) in untreated wounded group were significantly $(p<0.05)$ reduced by the MCSE when compared with wounded and ACSE groups (Figure 3A-C). However, ACSE showed trend towards reduction of the inflammatory markers but was not significant $(\mathrm{p}>0.05)$ when compared with wounded group. IL- $1 \beta$ and TNF- $\alpha$ remain significantly elevated following treatment with ACSE while IFN- $\gamma$ remain unchanged (Figure 3A-C).

\section{DISCUSSION}

The intricate cellular and molecular events, during acute wound healing, result in the elevated levels of reactive oxygen speciesand pro-inflammatory cytokines as observed in the current study (Nayak et al., 2009). These either prolong the inflammatory phase of acute wound healing or arrest wound healing at inflammation phase in chronic wounds. Generally, corn silk extracts enhance activities of the endogenous antioxidant enzymes, determined in the current study, with the methanolic extract remarkably increasing the enzymes' activities better than control and the aqueous extract. Similarly, both aqueous and methanolic extracts of corn silk ameliorate wound induced oxidative stress as revealed by the lower tissue level of MDA. However, methanolic corn silk extract only markedly reduced the tissue level of NO.

Evidently, methanolic corn silk extract consistently suppressed oxidative stress and reduced NO synthesis by enhancing antioxidant enzyme activities and controlling the activity of inducible nitric oxide synthase respectively to promote wound healing. Using different models of oxidative stress, studies have proven the potential antioxidant properties of corn silk extract both in vitro and in vivo. Corn silk extract efficiently scavenges free radicals and chelates the catalytic metal ions comparable to a reference compound in an in vitro study with a moderate nitric oxide-scavenging effect (Ebrahimzadeh et al., 2008). The study associated the antioxidant properties of corn silk extract to high amount of flavonoid and phenolic compounds detected in the extract. In another study, ferrulic acid was implicated as the main bioactive phytochemical in the corn silk that correlated strongly with the potent cellular antioxidant activity (Yang et al., 2019). Corn silk has been used successfully in the traditional management of diseases that are associated with oxidative stress mainly diabetes and diabetic complications such as diabetic nephropathy (Wang and Zhao, 2019). Our current findings support the fact that impaired wound healing is associated with redox imbalance leading to suppressed glutathione/ superoxide dismutase/catalase antioxidant defence and an increase in lipid peroxidation. This shift in redox status towards oxidative stress indicates the possibility of on-going tissue damage and consequent inflammatory responses. It is therefore noteworthy that MCSE and ACSE are potent enough to attenuate or normalise the oxidative damage that characterize delayed wound healing. Although MCSE showed greater potency and could be that methanol extracted more antioxidant phytochemicals from corn silk than water (Thoudam et al., 2011; Yang et al., 2019).

In addition, the current study has shown that methanolic corn silk extract produced not only marked antioxidant effect but also significant antiinflammation during wound healing. The aqueous corn silk extract also showed some inhibitory effect on IFN- $\gamma$ and COX-2 but methanolic corn silk extract considerably inhibited release of all the pro-inflammatory cytokine evaluated in the current study. Similar findings have been reported by Wang and his colleagues. They showed that pre-treatment of rat model of
A

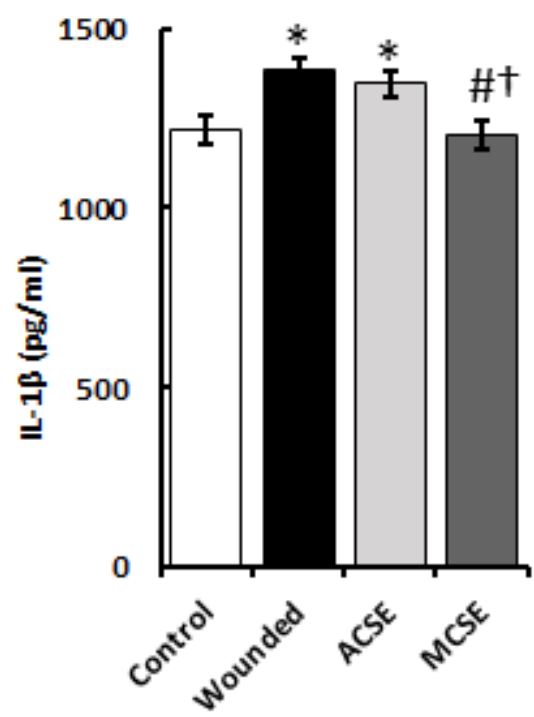

B

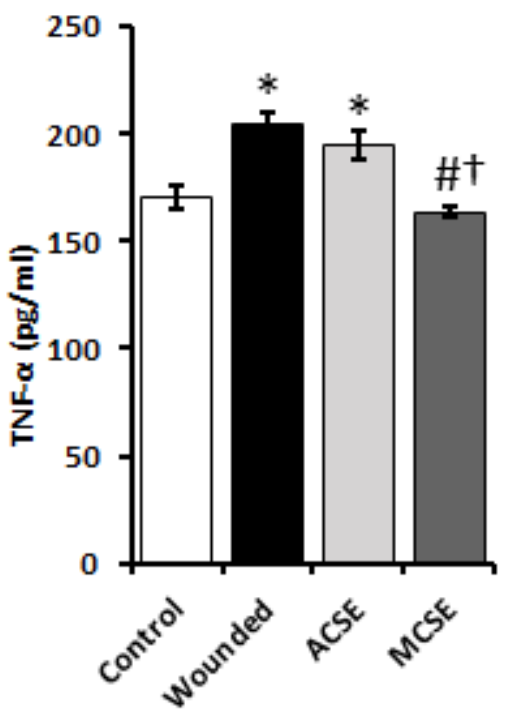

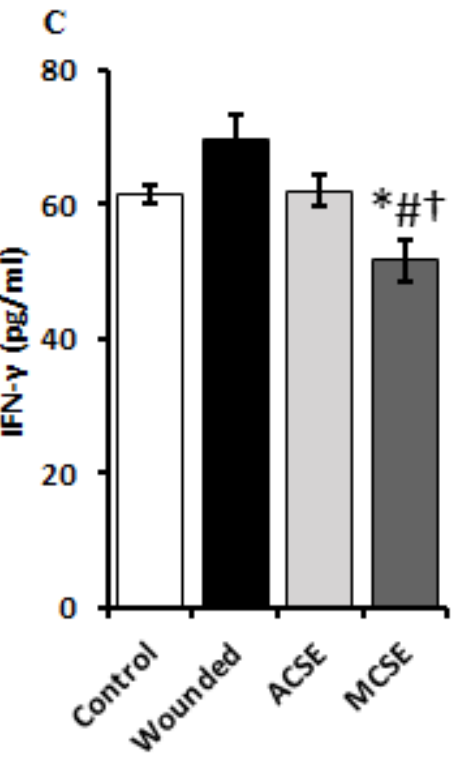

Figure 3: Serum levels of IL-1 $\beta$, TNF- $\alpha$, and IFN- $\gamma$ in wounded rats following treatment with corn silk extracts. ACSE, aqueous corn silk extract; MCSE, methanolic corn silk extract. Bars indicate mean $\pm \operatorname{SEM}(\mathrm{n}=5) ;{ }^{*}$, \#, and †indicate significant difference at $\mathrm{p}<0.05$ as compared with control, wounded and ACSE respectively. 
carrageenin-induced pleurisy with corn silk extract inhibited the inflammatory response by mechanisms associated with inhibition of TNF- $\alpha$, IL-1 $\beta$, VEGF- $\alpha$, and IL-17A. The extract also blocked inflammation-related events such as expressions of ICAM-1 and prooxidant enzymes iNOS by modulating NF-кB (Wanget al., 2012). Furthermore, corn silk displayed a remarkable anti-inflammatory activity, in vitro and in vivo, in a separate study targeting the bioactive peptide components of the protein rich aqueous corn silk extract and the trypsin hydrolysate of corn silk (Hoet al., 2017). Aqueous corn silk extract and the identified peptide from trypsin hydrolysate of corn silk extract, comparably interacted with IKK $\beta$ to inhibit the phosphorylation of I $\kappa$ B $\alpha$ thereby suppressing the activation of NF- $\kappa \beta$ (Hoet al., 2017). This explains the possible mechanism through which corn silk extract inhibited the release of all the inflammatory cytokines evaluated in the current study especially when the central role of NF- $\kappa \beta$ in transcriptional induction of pro-inflammatory cytokines is considered.

Although dose response effect is not recorded in this study, many previous studies have consistently reported the dose response effect of corn silk extracts in vitro and in vivo with a wide margin of safety and therapeutic window. A dose range of 50 to $300 \mathrm{mg} / \mathrm{kg}$ and 0.5 to $4.0 \mathrm{~g} / \mathrm{kg}$ have been administered in rodents for various biological activities for a period of 2 to 4 weeks. The single dose of the corn silk extracts $(500 \mathrm{mg} / \mathrm{kg})$, administered orally to the animals in the current study, is far below the high doses used in the previous studies that investigated the antioxidant and anti-inflammation properties of the corn silk extract in different animal models (Wang et al., 2012; Ha et al., 2018; Kim et al., 2019; Wang and Zhao, 2019). More so, the no-observed-adverse-effect level (NOAEL) of corn silk is reportedly $8.0 \% \mathrm{w} / \mathrm{w}$ when administered orally for 90 days. This corresponds to a mean daily corn silk intake of approximately 9.354 and $10.308 \mathrm{~g} /$ day $/ \mathrm{kg}$ body weight for males and females respectively (Wang et al., 2011).

There was no disparity among the studies reporting the anti-inflammatory and antioxidant properties of corn silk extracts in different models and disease conditions. However, different corn silk preparations were used. Corn silk extracts prepared using different organic solvents with varying polarity and aqueous extraction are commonly reported (Thoudam et al., 2011). It appears methods of extraction and extraction media have limited effect on the potency of corn silk extracts since different forms of the extract are consistently reported to have antiinflammatory and antioxidant properties. Though, this study suggests methanol as better extraction media and this is in line with the study by Thoudam et al., (2011). Till now, identification and characterization of phytochemicals that play predominant role in the anti-inflammation and antioxidant properties of corn silk are yet to be determined. Peptides and phenolic compounds extracted from corn silk using different methods and media have been indicated. Therefore, further study is required to divulge the optimum extraction method and characterised the most important candidate compound for molecular targeting in different pathologic condition involving inflammation and oxidative stress.

\section{CONCLUSIONS}

Wounds present two major conditions; increased oxidative stress (increased lipid peroxidation) as well as inflammatory response (increased production of proinflammatory cytokines). Corn silk provides protection against oxidative stress by inhibiting lipid peroxidation and reduced inflammation by inhibiting release of proinflammatory cytokines induced by wound in rat model. Inhibition of oxidative stress and inflammation accelerate wound healing and restore the functional and structural integrity of damaged tissues. It is also evident that methanolic corn silk extract produced a more notable effect relative to the aqueous corn silk extract. This is owing to the increased presence of some phytochemical constituents in methanol corn silk extract than in aqueous corn silk extract.

\section{ACKNOWLEDGMENT}

We would like to thank Human Physiology Research Laboratory Technicians and the Head of the Department of Physiology, University of Ilorin for their technical support and approving the use of their facility respectively.

\section{DECLARATION OF CONFLICT OF INTEREST}

Authors declare that they have no conflict of interest.

\section{DATA AVAILABITY STATEMENT}

The data sets used and analysed during the current study is available with the corresponding author upon request.

\section{REFERENCES}

Aebi, H., Wyss, S.R., Scherz, B. and Skvaril, F. (1974). Heterogeneity of erythrocyte catalase II: isolation and characterization of normal and variant erythrocyte catalase and their subunits. European Journal of Biochemistry 48(1): 137-145. doi: 10.1111/j.14321033.1974.tb03751.x.

Batool, R., Khan, M.R. and Majid, M. (2017). Euphorbia dracunculoides L. abrogates carbon tetrachloride induced liver and DNA damage in rats. BMC Complementary and Alternative Medicine 17(1): 223. doi: 10.1186/s12906-017-1744-x.

Bradford, M.M. (1976). A rapid and sensitive method for the quantitation of microgram quantities of protein utilizing the principle of protein-dye binding. Analytical Biochemistry 72(1-2): 248-254. doi: 10.1006/ abio.1976.9999.

Buege, J.A. and Aust, S.D. (1978). Microsomal lipid peroxidation. In: S. Fleischer, L. Packer (Eds), Methods in Enzymology, Academic Press, London 52: 302-310. doi: 10.1016/s0076-6879(78)52032-6.

Bump, E.A. and Brown, J.M. (1990). Role of glutathione in the radiation response of mammalian cells in vitro and in vivo. Pharmacology and Therapeutics 47(1): 117136. doi.org/10.1016/0163-7258(90)90048-7.

Cohen, G., Dembiec, D. and Marcus, J. (1970). Measurement of catalase activity in tissue extracts. Anal Biochem 34: 30-38. doi.org/10.1016/0003-2697(70)90083-7.

Ebrahimzadeh, M.A., Pourmorad, F. and Hafezi, S. (2008). Antioxidant activities of Iranian corn silk. Turkish 
Journal of Biology 32(1): 43-49.

Gilmore, M.A. (1991). Phases of wound healing, Dimensions in Oncology Nursing. Journal of the Division of Nursing 5(3): 32-34.

Guo, S.A. and DiPietro, L.A. (2010). Factors affecting wound healing. Journal of Dental Research 89(3): 219229. doi.org/10.1177/0022034509359125.

Ha, A.W., Kang, H.J., Kim, S.L., Kim, M.H. and Kim, W.K. (2018). Acute and subacute toxicity evaluation of corn silk extract. Preventive Nutrition and Food Science 23(1): 70-76. doi: 10.3746/pnf.2018.23.1.70.

Hasanudin, K., Hashim, P. and Mustafa, S. (2012). Corn silk (Stigma maydis) in healthcare: a phytochemical and pharmacological review. Molecules 17(8): 9697-9715. doi.org/10.3390/molecules17089697.

Haslina, H. and Eva, M. (2017). Extract corn silk with variation of solvents on yield, total phenolics, total flavonoids and antioxidant activity. Indonesian Food and Nutrition Progress 14(1): 21-28. doi.org/10.22146/ ifnp. 24280.

Ho, T.Y., Li, C.C., Lo, H.Y., Chen, F.Y. and Hsiang, C.Y. (2017). Corn silk extract and its bioactive peptide ameliorated lipopolysaccharide-induced inflammation in mice via the nuclear factor- $\mathrm{B}$ signaling pathway. Journal of Agricultural and Food Chemistry 65(4): 759-768. doi.org/10.1021/acs.jafc.6b03327.

Hoffmann, M.H. and Griffiths, H.R. (2018). The dual role of Reactive Oxygen Species in autoimmune and inflammatory diseases: evidence from preclinical models. Free Radical Biology and Medicine 125: 6271. doi.org/10.1016/j.freeradbiomed.2018.03.016.

Hu, Q.L. and Deng, Z.H. (2011). Protective effects of flavonoids from corn silk on oxidative stress induced by exhaustive exercise in mice. African Journal of Biotechnology 10(16): 3163-3167. doi: 10.5897/ AJB10.2671.

Järbrink, K., Ni, G., Sönnergren, H., Schmidtchen, A., Pang, C., Bajpai, R. and Car, J. (2016).Prevalence and incidence of chronic wounds and related complications: a protocol for a systematic review. Systematic Reviews 5(1): 152. doi.org/10.1186/s13643-016-0329-y.

Kim, Y.H., Cho, A., Kwon, S.A., Kim, M., Song, M., Shin, E.J., Park, E. and Lee, S.M. (2019). Potential photoprotective effect of dietary corn silk extract on ultraviolet B-induced skin damage. Molecules 24(14), 2587. doi.org/10.3390/molecules24142587.

Maksimović, Z., Malenčić, Đ. and Kovačević, N. (2005). Polyphenol contents and antioxidant activity of Maydis stigma extracts. Bioresource Technology 96(8): 873877. doi.org/10.1016/j.biortech.2004.09.006.

Marklund, S. and Marklund, G. (1974). Involvement of the superoxide anion radical in the autoxidation of pyrogallol and a convenient assay for superoxide dismutase. European Journal of Biochemistry 47(3): 469-474. doi.org/10.1111/j.1432-1033.1974.tb03714.x.

Marty, A.T. (1999). PDR for herbal medicines. The Journal of the American Medical Association 281(19): 18531854.

Nafiu, A.B. and Rahman, M.T. (2015). Anti-inflammatory and antioxidant properties of unripe papaya extract in an excision wound model. Pharmaceutical Biology
53(5): 662-671. doi.org/10.3109/13880209.2014.9364 70.

National Research Council. (2011). Animal care and use program. In: Guide for the Care and Use of Laboratory Animals, 8th edition, National Academies Press (US), Washington (DC).

Nayak, B.S., Sandiford, S. and Maxwell, A. (2009). Evaluation of the wound-healing activity of ethanolic extract of Morinda citrifolia L. leaf. Evidence-based Complementary and Alternative Medicine 6: 351-356. doi.org/10.1093/ecam/nem127.

Oyabambi, A.O., Areola, E.D., Olatunji, L.A. and Soladoye, A.O. (2020). Uric acid is a key player in salt-induced endothelial dysfunction: the therapeutic role of Stigma maydis (corn silk) extract. Applied Physiology, Nutrition, and Metabolism 45(1): 67-71. doi.org/10.1139/apnm-2018-0849.

Reddy, G.K. and Enwemeka, C.S. (1996). A simplified method for the analysis of hydroxyproline in biological tissues. Clinical Biochemistry 29(3): 225-229. doi. org/10.1016/0009-9120(96)00003-6.

Sorg, H., Tilkorn, D.J., Hager, S., Hauser, J. and Mirastschijski, U. (2017). Skin wound healing: an update on the current knowledge and concepts. European Surgical Research 58(1-2): 81-94. doi. org/10.1159/000454919.

Thoudam, B., Kirithika, T., Ramya, J. and Usha, K. (2011). Phytochemical constituents and antioxidant activity of various extracts of corn silk (Zea mays L). Research Journal of Pharmaceutical, Biological and Chemical Sciences 2(4): 986-993.

Wang, C., Zhang, T., Liu, J., Lu, S., Zhang, C., Wang, E., Wang, Z., Zhang, Y. and Liu, J. (2011). Subchronic toxicity study of corn silk with rats. Journal of Ethnopharmacology 137(1): 36-43. doi.org/10.1016/j. jep.2011.03.021.

Wang, G.Q., Xu, T., Bu, X.M. and Liu, B.Y. (2012). Antiinflammation effects of corn silk in a rat model of carrageenin-induced pleurisy. Inflammation 35(3): 822827. doi.org/10.1007/s10753-011-9382-9.

Wang, K.J. and Zhao, J.L. (2019). Corn silk (Zea mays L.), a source of natural antioxidants with $\alpha$-amylase, $\alpha$-glucosidase, advanced glycation and diabetic nephropathy inhibitory activities. Biomedicine and Pharmacotherapy 110: 510-517. doi.org/10.1016/j. biopha.2018.11.126.

Witsell, A.L. and Schook, L.B. (1992). Tumor necrosis factor alpha is an autocrine growth regulator during macrophage differentiation. Proceedings of the National Academy of Sciences 89(10): 4754-4758. doi. org/10.1073/pnas.89.10.4754.

Witte, M.B. and Barbul, A. (2002). Role of nitric oxide in wound repair. The American Journal of Surgery 183(4): 406-412. doi.org/10.1016/S0002-9610(02)00815-2.

Yang, T., Guang Hu, J., Yu, Y., Li, G., Guo, X., Li, T. and Liu, R.H. (2019). Comparison of phenolics, flavonoids, and cellular antioxidant activities in ear sections of sweet corn (Zea mays L. saccharata Sturt). Journal of Food Processing and Preservation 43(1): e13855. doi. org/10.1111/jfpp.13855. 